\title{
Neuronal accumulation of unrepaired DNA in a novel specific chromatin domain: structural, molecular and transcriptional characterization
}

\author{
Jorge Mata-Garrido, Iñigo Casafont, Olga Tapia, Maria T. Berciano and Miguel Lafarga*
}

\begin{abstract}
There is growing evidence that defective DNA repair in neurons with accumulation of DNA lesions and loss of genome integrity underlies aging and many neurodegenerative disorders. An important challenge is to understand how neurons can tolerate the accumulation of persistent DNA lesions without triggering the apoptotic pathway. Here we study the impact of the accumulation of unrepaired DNA on the chromatin architecture, kinetics of the DNA damage response and transcriptional activity in rat sensory ganglion neurons exposed to 1-to-3 doses of ionizing radiation (IR). In particular, we have characterized the structural, molecular and transcriptional compartmentalization of unrepaired DNA in persistent DNA damaged foci (PDDF). IR induced the formation of numerous transient foci, which repaired DNA within the $24 \mathrm{~h}$ post-IR, and a 1-to-3 PDDF. The latter concentrate DNA damage signaling and repair factors, including $\mathrm{YH}$ 2AX, PATM, WRAP53 and 53BP1. The number and size of PDDF was dependent on the doses of IR administered. The proportion of neurons carrying PDDF decreased over time of post-IR, indicating that a slow DNA repair occurs in some foci. The fine structure of PDDF consisted of a loose network of unfolded $30 \mathrm{~nm}$ chromatin fiber intermediates, which may provide a structural scaffold accessible for DNA repair factors. Furthermore, the transcription assay demonstrated that PDDF are transcriptionally silent, although transcription occurred in flanking euchromatin. Therefore, the expression of $\mathrm{YH} 2 \mathrm{AX}$ can be used as a reliable marker of gene silencing in DNA damaged neurons. Moreover, PDDF were located in repressive nuclear environments, preferentially in the perinucleolar domain where they were frequently associated with Cajal bodies or heterochromatin clumps forming a structural triad. We propose that the sequestration of unrepaired DNA in discrete PDDF and the transcriptional silencing can be essential to preserve genome stability and prevent the synthesis of aberrant mRNA and protein products encoded by damaged genes.
\end{abstract}

Keywords: DNA damage and repair centers, Accumulation of unrepaired DNA, Neurons, Nuclear compartments, Transcription, Genome stability

\section{Introduction}

Cellular DNA damage response (DDR) is a molecular signaling pathway that is strongly induced by cytotoxic DNA lesions, such as double strand breaks (DSBs) which are produced by endogenous or exogenous genotoxic agents. In neurons, the DDR is mediated by the kinase ATM,

\footnotetext{
* Correspondence: lafargam@unican.es

Departamento de Anatomía y Biología Celular and "Centro de Investigación Biomédica en Red sobre Enfermedades Neurodegenerativas (CIBERNED)", Universidad de Cantabria-IDIVAL, Avda. Cardenal Herrera Oria s/n, Santander, Spain
}

which phosphorylates crucial protein partners in this pathway [1]. Mammalian neurons are highly vulnerable to DNA damage due to their high metabolic rate for energy production, generating cytotoxic reactive oxygen species (ROS) that can produce oxidative DNA damage. In addition, the relaxed chromatin configuration (euchromatin) of the majority of neuronal populations facilitates genotoxic agents gaining access to DNA and disrupting its structure $[2,3]$. Cytotoxic DSBs can be derived from the conversion of single-strand breaks (SSBs) into DSBs or can be induced by environmental agents, such as ionizing radiation (IR), including X-rays, and chemotherapeutic drugs. They are 
especially detrimental for neurons as they affect genome integrity and global transcriptional activity [3-5]. Moreover, DSBs can produce energy starvation given that the DDR is a very high ATP consuming process [6]. Since post-mitotic neurons lack sister chromatids that serve as a template to ensure "error-free" repair by homologous recombination (HR), DSBs need to be repaired by non-homologous end joining (NHEJ) [7]. Due to the fact that DSB ends need to be processed before religation, errors can be introduced in NHEJ repair, resulting in neuronal dysfunction which ultimately contribute to neurodegeneration [8].

In addition to diseases with neurological manifestations caused by mutations in DNA repair factors, there is increasing evidence that defective DNA repair with an accumulation of DNA lesions and loss of genome stability underlies aging and many neurodegenerative disorders in human patients and animal experimental models $[6,9-12]$. It has recently been reported that accumulated DNA damage can produce a deregulated DDR, leading to a senescence-like phenotype in neurons [9].

DDR occurs in the context of chromatin and requires elaborated epigenetic changes of histones in DNA damaged sites and flanking regions to stabilize broken DNA ends, in order to facilitate access of repair factors to damaged sites $[8,13]$. Notwithstanding the extensive evidence of DNA damage-associated changes in the epigenome, it still remains unclear how neurons tolerate the accumulation of DNA lesions and how neurons process DNA damage in chromatin compartments and sequestrated unrepaired DNA in a few persistent DNA damage foci (PDDF) with a non-random spatial organization.

In a previous study, using an experimental model of DNA damage in rat sensory ganglion neurons (SGNs) with IR (4 Gy), we demonstrated that the neuronal DDR includes the formation of two categories of DNA-damage chromatin compartments [3]. The first are transient small and very numerous foci, which disappear within the first day post-IR, reflecting an effective DNA repair. The second consist of a few PDDF where unrepaired DNA is accumulated and remained at 15 days post-IR. Furthermore this neuronal DDR does not induce apoptosis but triggers G0G1 cell cycle transition [3]. In this context, SGNs exposed to IR provide an excellent experimental system for investigating the nuclear organization and fate of unrepaired DNA accumulated in PDDF. Moreover, IR with a sub-lethal dose (4 Gy) in rodents triggers DDR, prevents neuronal apoptosis and makes it possible to study the long-term compartmentalization and dynamic of unrepaired DNA and its relationships with specific chromatin modifications and transcription rate. Finally, due to the absence of blood brain barrier in peripheral ganglia, the DNA damage-induced dysfunction of SGNs is a main component in peripheral neuropathies caused by cancer chemotherapy $[14,15]$. In this study we analyze the following in irradiated SGNs i) the spatiotemporal organization of PDDF, ii) the molecular composition of these foci, iii) the ultrastructural compartmentalization of PDDF in cleared chromatin domains with unfolded chromatin fibers, iv) the transcriptional activity of PDDF and flanking chromatin domains, and v) the specific spatial association of PDDF with nuclear compartments which promotes gene silencing.

\section{Materials and methods \\ Animals}

Experiments were designed and performed to minimize the use of animals using a total of 72 young (30 days old) male Sprague-Dawley rats, distributed in a control (nonirradiated, $n=9$ ) and five experimental groups treated with X-ray ionizing radiation ( $n=9$ per group). The animals were housed with a 12-h light/dark cycle and had free access to food and water. The animals were kept, handled, and sacrificed in accordance with the directives of the Council of the European Communities and current Spanish legislation, and the experiments were approved by the Bioethical Committee of the University of Cantabria.

\section{X-ray irradiation}

Exogenous DNA damage was induced by X-Ray irradiation using an X-Ray generator system (Maxishot-d, Yxlon, Int. USA) equipped with an X-Ray tube which works at $200 \mathrm{kV}$ and $4.5 \mathrm{~mA}$. The animals, deeply anesthetized with pentobarbital $(50 \mathrm{mg} / \mathrm{kg})$, were placed $25 \mathrm{~cm}$ away from the X-Ray source that generated an X-Ray beam with an absorbed dose rate of approximately $0.9 \mathrm{~Gy} /$ min. The animal's body was protected with a lead tube, exposing only the head, and the beam focused on the head to avoid adverse effects on the bone marrow, spinal cord and any other tissues produced by global animal radiation. The animals were exposed to IR for $4 \mathrm{~min}$ and $20 \mathrm{~s}$ in order to administrate a sub-lethal dose of 4Gy, a reference dose in DNA damage/repair experiments [3]. For this work we used control and irradiated animals with one, two or three doses of IR (4Gy each) as indicated in the experimental plan of the Table 1 . The animals were sacrificed and the trigeminal sensory ganglia were processed for different cell biology and biochemical methods.

\section{Immunofluorescence and confocal microscopy}

For light immunocytochemistry, the animals ( $n=3$ animals per group) deeply anesthetized as described above were perfused with the fixative solution containing $3.7 \%$ formaldehyde (freshly prepared from paraformaldehyde) in PBS. Tissue fragments of trigeminal ganglia were removed and washed in PBS. For immunofluorescence, each tissue fragment was transferred to a drop of PBS on a siliconized slide (SuperFrostPlus, Menzel-Gläser, Germany) and squash preparations of dissociated neurons were 
Table 1 Summary of the experimental plan

\begin{tabular}{|c|c|c|c|c|}
\hline Animals & $\begin{array}{l}30 \text { Days } \\
\text { old }\end{array}$ & $\begin{array}{l}45 \text { Days } \\
\text { old }\end{array}$ & $\begin{array}{l}60 \text { Days } \\
\text { old }\end{array}$ & $\begin{array}{l}75 \text { Days } \\
\text { old }\end{array}$ \\
\hline Control & - & Sacrifice & - & - \\
\hline \multirow[t]{3}{*}{$\begin{array}{l}1 \text { Dose of X-Ray } \\
\text { irradiation }\end{array}$} & $\begin{array}{l}\text { Irradiation } \\
\text { 4Gy }\end{array}$ & Sacrifice & - & - \\
\hline & $\begin{array}{l}\text { Irradiation } \\
\text { 4Gy }\end{array}$ & - & Sacrifice & - \\
\hline & $\begin{array}{l}\text { Irradiation } \\
\text { 4Gy }\end{array}$ & - & - & Sacrifice \\
\hline $\begin{array}{l}2 \text { Doses of X-Ray } \\
\text { irradiation }\end{array}$ & $\begin{array}{l}\text { Irradiation } \\
\text { 4Gy }\end{array}$ & $\begin{array}{l}\text { Irradiation } \\
\text { 4Gy }\end{array}$ & Sacrifice & - \\
\hline $\begin{array}{l}3 \text { Doses of X-Ray } \\
\text { irradiation }\end{array}$ & $\begin{array}{l}\text { Irradiation } \\
\text { 4Gy }\end{array}$ & $\begin{array}{l}\text { Irradiation } \\
\text { 4Gy }\end{array}$ & $\begin{array}{l}\text { Irradiation } \\
4 \mathrm{~Gy}\end{array}$ & Sacrifice \\
\hline
\end{tabular}

performed following the previously reported procedure [16]. The samples were sequentially treated with $0.1 \mathrm{M}$ glycine in PBS for 15 min, 3 \% BSA in PBS for 30 min and $0.5 \%$ Triton X-100 in PBS for $45 \mathrm{~min}$. They were then incubated with the primary antibody overnight at $4{ }^{\circ} \mathrm{C}$, washed with $0.05 \%$ Tween 20 in PBS, incubated for $45 \mathrm{~min}$ in the specific secondary antibody conjugated with FITC or TexasRed (Jackson, USA), washed in PBS and mounted with the antifading medium ProLong (Invitrogen, USA). Some samples were counterstained with DAPI, a cytochemical marker of DNA.

Confocal images were obtained with a LSM510 (Zeiss, Germany) laser scanning microscope and using a 63x oil (1.4 NA) objective. In order to avoid overlapping signals, images were obtained by sequential excitation at 355 , 488 and $543 \mathrm{~nm}$ in order to detect DAPI, FITC and Texas Red, respectively. Emission signals were detected at $405-450 \mathrm{~nm}$ for DAPI, 505-530 nm for FITC and $>560$ for Cy3 or Texas Red. Images were processed using Photoshop software.

The proportion of damaged SGNs containing IRinduced PDDF and the number of foci per neuron was determined by direct examination of dissociated neurons, in which the whole neuronal body is preserved, immunostained for $\gamma \mathrm{H} 2 \mathrm{AX}$ and using a $40 \mathrm{X}$ objective. At least 100 neurons per animal were examined $(n=3$ animals per group). Planimetric measurements of PDDF areas were made on confocal microscopy images of sensory ganglion neurons immunostained for the $\gamma \mathrm{H} 2 \mathrm{AX}$, using a $63 \mathrm{X}(1.4 \mathrm{NA})$ immersion oil objective. Image processing and measurement steps were performed on ImageJ, public domain software for image analysis (NIH, Bethesda, Maryland, USA; http://rsb.info.nih.gov/ij/). The average PDDF area was estimated on at least 30 nuclear confocal sections of neurons per animal ( $n=3$ animals per group). Average values were pooled for subsequent graphing and analysis. Data were analyzed using Microsoft Excel and the analysis of variance was used to determine the statistical significance of differences between control and irradiated neurons of sensory ganglia. Values are Means $\pm \mathrm{SD}$.

\section{Transmission electron microscopy}

For conventional, immunogold and ultrastructural electron microscopy examination of SGNs, control and irradiated rats ( $n=3$ animals per group) were perfused under deep anesthesia with $3.7 \%$ paraformaldehyde in $0.1 \mathrm{M}$ cacodylate buffer for $10 \mathrm{~min}$ at room temperature. Small tissue fragments of trigeminal ganglia were washed in $0.1 \mathrm{M}$ cacodylate buffer, dehydrated in increasing concentrations of methanol at $-20^{\circ} \mathrm{C}$, embedded in Lowicryl $\mathrm{K} 4$ $\mathrm{M}$ at $-20^{\circ} \mathrm{C}$ and polymerized with ultraviolet irradiation. Ultrathin sections were mounted on nickel grids and were stained with lead citrate and uranyl acetate and examined with a JEOL 1011 electron microscope. Some ultrathin sections were processed for the EDTA staining procedure for ribonucleoproteins. For immunogold electron microscopy, sections were sequentially incubated with $0.1 \mathrm{M}$ glycine in PBS for 15 min, 5 \% BSA in PBS for $30 \mathrm{~min}$ and the primary antibody for $2 \mathrm{~h}$ at $37{ }^{\circ} \mathrm{C}$. After washing, the sections were incubated with the specific secondary antibodies coupled to $10 \mathrm{~nm}$ gold particles (BioCell, UK; diluted 1:50 in PBS containing $1 \%$ BSA). Following immunogold labeling, the grids were stained with lead citrate and uranyl acetate. As controls, ultrathin sections were treated as described above but with the primary antibody omitted.

\section{Run-on transcription assays in situ}

Active transcription sites were labeled by the incorporation of 5'-fluorouridine (5'-FU) into nascent RNA. Briefly, under anesthesia both control and irradiated rats ( $n=3$ animals per group) were given an intravenous injection of 5'-FU (Sigma, UK) of a stock solution of $0.4 \mathrm{M} 5^{\prime}$-FU in $0.9 \%$ saline at doses of $5 \mu \mathrm{l} / \mathrm{g}$. All animals were sacrificed after $45 \mathrm{~min}$ post-injection of the halogenated nucleotide and fixed by perfusion with $3.7 \%$ paraformaldehyde in HPEM buffer (2x HPEM: Hepes, $60 \mathrm{mM}$; Pipes, $130 \mathrm{mM}$; EGTA, $20 \mathrm{mM}$; and $\mathrm{MgCl}_{2} \cdot 6 \mathrm{H}_{2} \mathrm{O}, 4 \mathrm{mM}$ ) containing $0.5 \%$ Triton X-100 for $10 \mathrm{~min}$. Trigeminal ganglia were removed, washed in HPEM buffer containing $0.5 \%$ Triton X-100 for $10 \mathrm{~min}$ and cut into small fragments. Then tissue fragments were washed in 0.1 M HPEM buffer, dehydrated in increasing concentrations of methanol at $-20{ }^{\circ} \mathrm{C}$, embedded in Lowicryl K4 M at $-20{ }^{\circ} \mathrm{C}$ and polymerized with ultraviolet irradiation. Ultrathin sections were mounted on nickel grids and sequentially incubated with $0.1 \mathrm{M}$ glycine in PBS for $15 \mathrm{~min}, 5$ \% BSA in PBS for $30 \mathrm{~min}$ and the mouse monoclonal anti-BrdU (clone BU-33, Sigma, UK) antibody (diluted 1:25 in $50 \mathrm{mM}$ Tris $-\mathrm{HCl}$, $\mathrm{pH} 7.6$, containing $1 \% \mathrm{BSA}$ and $0.1 \mathrm{M}$ glycine) for $1 \mathrm{~h}$ at $37{ }^{\circ} \mathrm{C}$. After washing, the sections were incubated 
with an anti-mouse secondary antibody coupled to $15 \mathrm{~nm}$ gold particles (BioCell, UK; diluted 1:50 in PBS containing $1 \%$ BSA). Following immunogold labeling, the grids were stained with lead citrate and uranyl acetate and examined with a JEOL 1011 electron microscope. As controls, ultrathin sections were treated as described above but with the primary antibody omitted.

\section{SDS-PAGE and Immunoblotting}

Trigeminal ganglia from control and irradiated rats $(n=3$ animals per group) were lysed using a Polytron PT-2000 (Kinematica ${ }^{\oplus}$, Luzern-Switzerland) on ice in cold extraction buffer NETN [20 mM Tris- $\mathrm{HCl}$ pH 8.0, $500 \mathrm{mM} \mathrm{NaCl}$, $1 \mathrm{mM}$ EDTA] containing Benzonase $(1 \mu \mathrm{L} / 1 \mathrm{~mL}$ lysis buffer) (Novagen) and supplemented with protease and phosphatase inhibitor cocktail (Halt ${ }^{\mathrm{TM}}$ Protease and Phosphatase inhibitor single use cocktail, Thermo Scientific, USA) and incubated for $30 \mathrm{~min}$ on ice. After centrifugation (12 min at $12000 \mathrm{rpm}$ ) at $4{ }^{\circ} \mathrm{C}$ the supernatant was frozen. Proteins were separated on SDS-PAGE gels and transferred to nitrocellulose membranes by standard procedures. Protein bands were detected with an OdysseyTM Infrared-Imaging System (Li-Cor Biosciences) according to OdysseyTM Western-Blotting Protocol. Immunoblots were developed with anti-mouse IRDye800DX or anti-rabbit IRDye700DX (Rockland Immunochemicals, USA) secondary antibodies.

\section{Antibodies}

The primary antibodies used and their dilutions for immunofluorescence, immunogold electron microscopy and Western blotting are described in Table 2. Specific secondary antibodies conjugated with FITC, TexasRed or Cy3 (Jackson Lab., USA) were used for immunofluoescence.

\section{Results}

\section{Organization and dynamics of PDDF induced by IR in SGNs}

The organization and dynamics of PDDF were analyzed in mechanically dissociated perikarya of SGNs exposed to one (4Gy), two (4Gy x 2) or three (4Gy x 3) doses of IR and double immunolabeled for phosphorylated histone $\mathrm{H} 2 \mathrm{AX}(\gamma \mathrm{H} 2 \mathrm{AX})$, a well-established marker of DSBs $[17,18]$, and also 53BP1, a key factor that protects DNA ends from resection and promotes DNA repair by the NHEJ $[19,20]$. In control neurons the nuclear expression of $\gamma \mathrm{H} 2 \mathrm{AX}$ was barely detectable, whereas 53BP1 displayed a diffuse nuclear expression (Fig. 1a). In contrast, numerous and small transient DNA damage foci immunoreactive for $\gamma \mathrm{H} 2 \mathrm{AX}$ and 53BP1 were observed at $3 \mathrm{~h}$ post-IR (Fig. 1b). As previously reported [3], most of them disappeared within the first $24 \mathrm{~h}$ post-IR indicating an effective DNA repair.

In this study we have focused on the organization and behavior of $\gamma \mathrm{H} 2 \mathrm{AX}$ - and 53BP1-positive PDDF that remained over longer terms, at 15, 30 and 45 days post-IR (Fig. 1c-f). They reflect the neuronal processing of irreparable or very slowly repaired DNA. A very small proportion of control neurons showed isolated PDDF, which presumably correspond to endogenous, spontaneous DNA damage (Fig. 1g, h). The global proportion of PDDF-containing SGNs after a single dose of IR was approximately $32 \%$ at 15 days post-IR, decreasing significantly $(20 \%)$ at 45 days post-IR (Fig. 1g). These findings support slow, long-term DNA repair in this neuronal population. Furthermore, the proportion of neurons with PDDF significantly increased when SGNs were exposed to double or triple IR doses (up to $72 \%$ ), as compared with those irradiated with a single dose (Fig. 1h). This observation clearly indicates that the neuronal accumulation of unrepaired DNA in PDDF is dependent on the total dose of IR. Next we determined the mean number of PDDF per nucleus and the size of these foci in DNA damaged neurons. Whereas most of the neurons exposed to a single dose of IR carried one or less frequently two large PDDF at 15 days post-IR, the administration of two or three doses of IR was associated with a parallel significant increase in both the number and size of PDDF (Fig. 1i-l, graphs $\mathrm{m}, \mathrm{n}$ ), indicating a dose-dependent accumulation of DNA damage. These findings were confirmed by Western blotting for $\gamma \mathrm{H} 2 \mathrm{AX}$ in sensory ganglion lysates. While the phosphorylated H2AX was barely detectable in non-irradiated ganglion, a notable and dosedependent increase of protein levels was observed in irradiated ganglion (Fig. 10).

\section{PDDF concentrate essential components of the DNA damage/repair signaling pathway}

In order to rule out the possibility that PDDF were a simple DNA-free reservoir of protein components of DDR, we performed DNA staining with DAPI in combination with immunolabeling for $\gamma \mathrm{H} 2 \mathrm{AX}$. As shown in Fig. $2 \mathrm{a}-\mathrm{c}, \mathrm{DNA}$ is present in PDDF, appearing as a diffuse signal of moderate intensity as compared with the strongly stained perinuclear heterochromatin.

In addition to $\gamma \mathrm{H} 2 \mathrm{AX}$ and 53BP1, we investigated the recruitment in PDDF of three essential factors for DNA repair: phosphorylated ATM (pATM), ubiquitylated H2A (Ub-H2A) and WRAP53 (WD40 encoding RNA antisense to $\mathrm{p} 53$ ) ( $n=30$ neurons per animal). Since ATM kinase is a fundamental DSBs sensor for triggering DDR [21], we analyzed the recruitment of active autophosphorylated ATM to PDDF. Double immunolabeling for pATM and $\gamma \mathrm{H} 2 \mathrm{AX}$ revealed the colocalization of both molecular components in the PDDF examined (Fig. 2d-f). Given that chromatin remodeling at DNA damage sites is required for repair factors can access to DSBs, we analyzed the ubiquitylation of the histone $\mathrm{H} 2 \mathrm{~A}$ and the recruitment of WRAP53 to PDDF. Whereas Ub-H2A promotes 
Table 2 Antibodies used in this study

\begin{tabular}{|c|c|c|c|c|}
\hline Antibody & Marker & Type & Origin (Reference) & Technique and Dilution \\
\hline Anti-Alpha-Tubulin & Loading Control & Mouse Monoclonal & Sigma (T9026) & WB $(1: 1000)$ \\
\hline Anti-BrdU & Transcription Assay & Mouse Monoclonal & Sigma (B8434) & IE (1:50) \\
\hline Anti-Fibrillarin & Nucleolus & Mouse Monoclonal & ABCAM (ab4566) & IF $(1: 500)$ \\
\hline \multirow[t]{2}{*}{ Anti-Histone H2AX phospho-Ser139 } & DNA Damage & Mouse Monoclonal & Millipore (05-636) & WB $(1: 1000)$ \\
\hline & & & & IF $(1: 200)$ \\
\hline Anti-HP1 gamma & Heterochromatin & Mouse Monoclonal & Millipore (05-689) & IF $(1: 100)$ \\
\hline Anti-RNA Pol II H5 antibody & Transcription sites & Mouse Monoclonal & Covance (MMS-129R) & IE (1:50) \\
\hline Anti-TMG Cap & Nuclear Speckle (IGC) & Mouse Monoclonal & Oncogene (NA02A) & IF $(1: 100)$ \\
\hline \multirow[t]{3}{*}{ Anti-WRAP53 } & DNA Damage & Mouse Monoclonal & ABNOVA (H00055135-M04) & WB $(1: 2000)$ \\
\hline & & & & IF $(1: 200)$ \\
\hline & & & & IE $(1: 100)$ \\
\hline \multirow[t]{3}{*}{ Anti-53BP1 } & DNA Damage/repair & Rabbit Polyclonal & Bethyl Laboratories (A300-272A) & WB (1:1000) \\
\hline & & & & IF $(1: 250)$ \\
\hline & & & & IE (1:50) \\
\hline \multirow[t]{2}{*}{ Anti-ATM Phospho-Ser1981 } & DNA Damage & Rabbit Polyclonal & Cell Signaling (4526) & WB (1:500) \\
\hline & & & & IF $(1: 100)$ \\
\hline \multirow[t]{2}{*}{ Anti-Coilin 210.4 antibody } & Cajal Body & Rabbit Polyclonal & Provided by Prof. A.I. Lamond & IF $(1: 250)$ \\
\hline & & & & IE (1:50) \\
\hline Anti-Fibrillarin 12.3 antibody & Nucleolus & Rabbit Polyclonal & Provided by Prof. M.Carmo-Fonseca & IE $(1: 100)$ \\
\hline Anti-Histone H2AX phospho-Ser139 & DNA Damage & Rabbit Polyclonal & Novus (NB100-384) & IF $(1: 200)$ \\
\hline Anti-Trimethyl-Histone H4 (Lys 20) & Heterochromatin & Rabbit Polyclonal & Millipore (07-463) & IF $(1: 250)$ \\
\hline \multirow[t]{2}{*}{ Anti-Ubiquityl H2A } & DNA Damage & Rabbit Polyclonal & Millipore (05-678) & WB (1:1000) \\
\hline & & & & IF $(1: 100)$ \\
\hline
\end{tabular}

WB western blotting, IF immunofluorescence microscopy, IE immunogold electron microscopy

chromatin remodeling and the assembly of repair factors to DSBs [22, 23], WRAP53 regulates histone ubiquitylation and provides a scaffold for DNA repair factors [24]. Coimmunostaining of Ub-H2A or WRAP53 with 53BP1 revealed the concentration of the first two in 53BP1-positive PDDF, regardless of the IR dose that was administered (Fig. 2g-l). The IR-induced and dose-dependent increase in the expression levels of pATM and Ub-H2A was corroborated with Western blotting of sensory ganglion lysates (Fig. 2m, n). On the other hand, basal levels of WRAP53 were detected in control sensory ganglion and a slight increase in protein levels was registered after IR treatment (Fig. 2o). Collectively, the presence in PDDF of essential components of the DNA damage/repair machinery indicates that DNA damage signaling continues long-term after IR.

\section{Ultrastructural organization of chromatin in PDDF and flanking domains}

To determine the structural chromatin organization in PDDF we performed conventional electron microscopy and ultrastructural immunogold for 53BP1 and WRAP53. By electron microscopy of tissue samples which were fixed with $4 \%$ paraformaldehyde and embedded in Lowicryl 4KM, PDDF appeared as well-defined cleared nucleoplasmic areas in euchromatin regions and were preferentially located at the nucleolar and nuclear periphery (Fig. 3a, b). At a high magnification, PDDF exhibited deep relaxation of chromatin structure, which was composed of a network of tiny fibers and commonly surrounded by euchromatin regions (Fig. 3c). With the EDTA preferential staining for ribonucleoproteins [25], the RNA-rich nuclear structures, including the ribonuceoproteins of euchromatin and interchromatin granule clusters ("nuclear speckles" at light microscopy level, [26]), were intensely stained. In contrast, PDDF stood out against the adjacent euchromatin because of their electron-lucent appearance, indicating a reduced concentration of ribonucleoproteins (Fig. 3d).

With the immunogold electron microscopy for DNA repair factor 53BP1, PDDF were sharply defined by their intense immunolabeling (Fig. 4a). In particular, gold particles of 53BP1 immunoreactivity specifically decorated a fibers network within foci, whereas the associated nucleoplasm was free of labeling (Fig. 4b). Importantly, 53BP1-positive fibers ranged in diameter from smaller (about $11 \mathrm{~nm}$ ), which may correspond to nucleosomal 


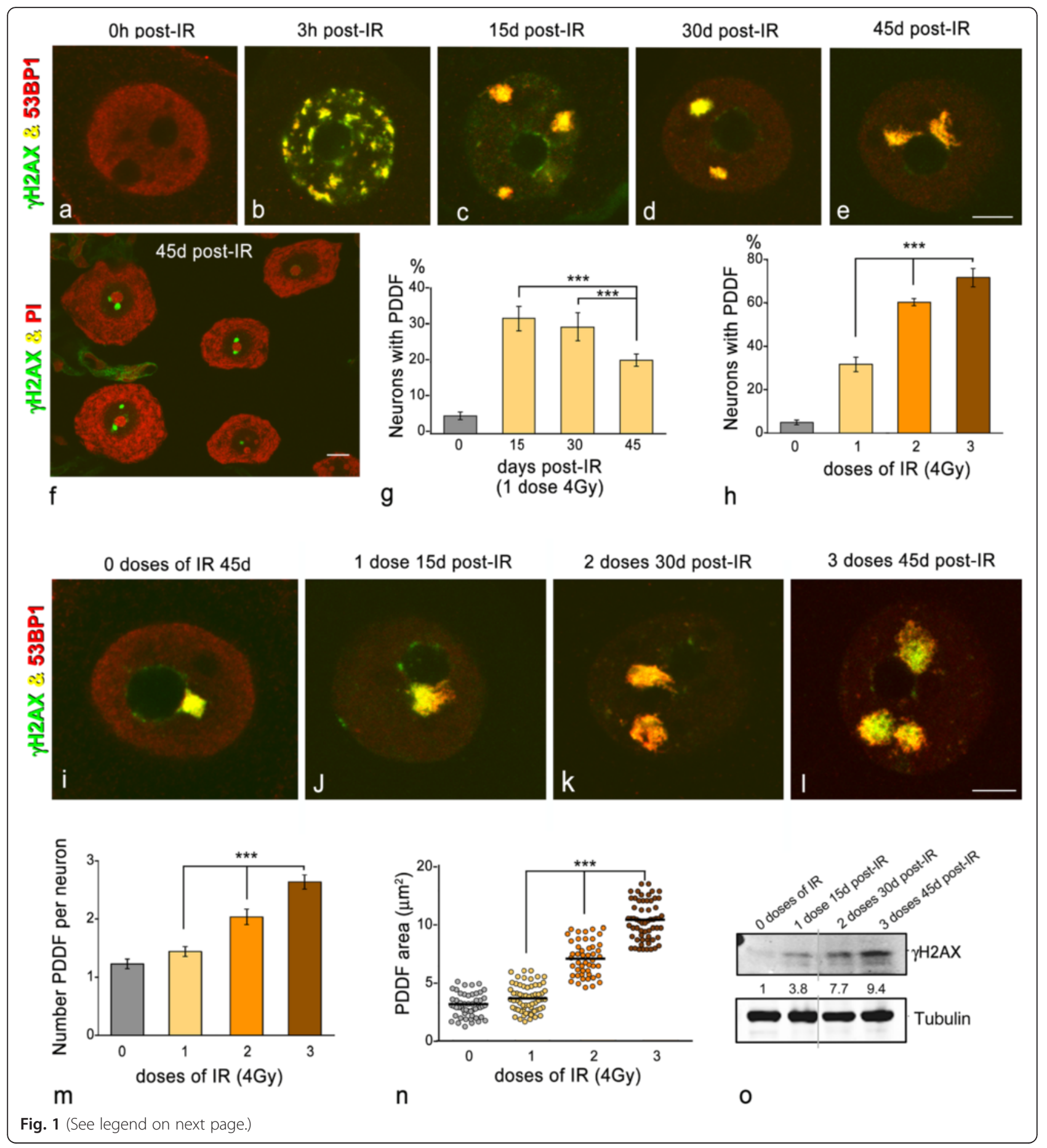




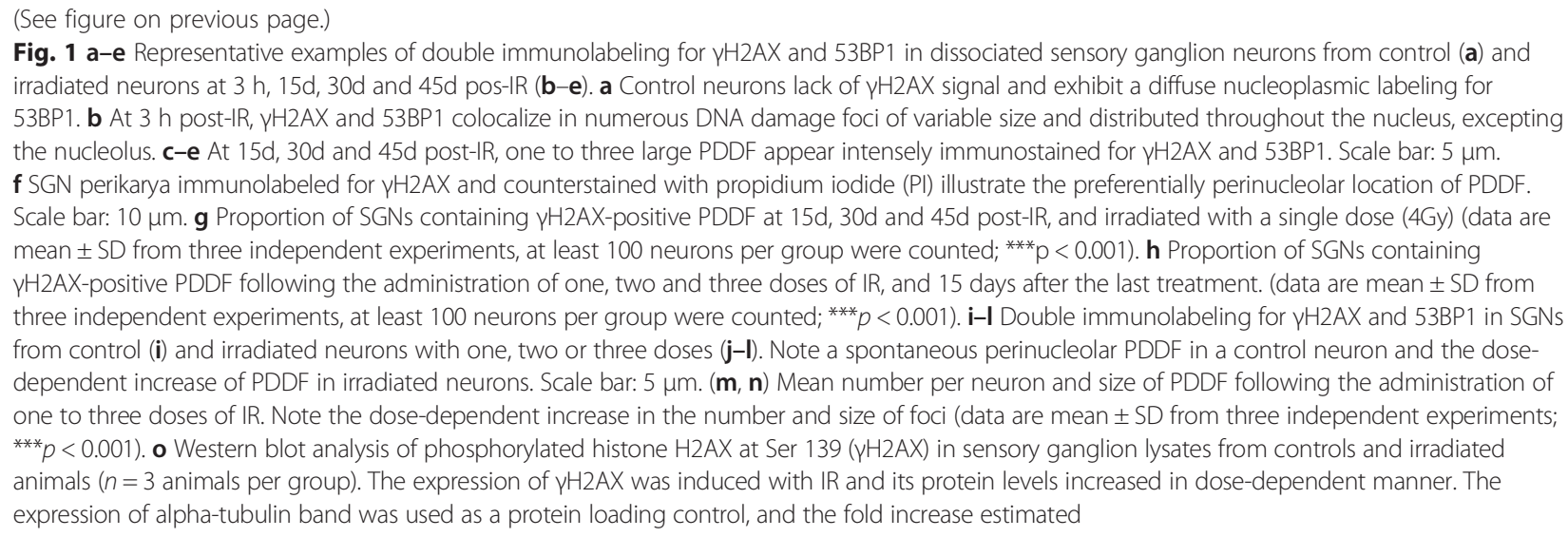

chains, to larger fibers (about $30 \mathrm{~nm}$ ), a diameter characteristic of chromatin fibers [27]. This finding strongly supports the fact that the PDDF contain unfolded chromatin fibers with increased accessibility of DNA to repair factors. Regarding the immunogold labeling for WRAP53, gold particles also decorated PDDF fibers, although at a lower intensity than 53BP1 (Fig. 4c). No differences in the fine structure and immunogold labeling of PDDF were observed regardless of the total IR doses administered.

\section{PDDF are transcriptionally silent, but active transcription occurs in flanking chromatin}

To analyze the transcriptional activity in PDDF and flanking chromatin domains, we performed an in situ transcription assay using the high resolution immunogold electron microscopy. This procedure is based on the incorporation of the RNA precursor 5'-FU into nascent RNA. After a 45-min pulse of 5'-FU incorporation, immunogold particles decorated the extensive nuclear domains of euchromatin (Fig. 5a, b), where active protein-coding genes are distributed. Additionally, an intense 5'-FU incorporation was also detected in the dense fibrillar component of the nucleolus (Fig. 5c), the site of transcription of ribosomal genes [28]. As expected, immunogold particles were absent from transcription-free nuclear compartments such as Cajal bodies (Fig. 5c). Importantly, nascent RNA was not detected in PDDF, with their network of unfolded chromatin fibers appearing free of gold particles (Fig. 5a-c). However, an active transcription was observed in flanking euchromatin, establishing a sharply defined boundary between transcriptionally permissive chromatin and non-permissive DNA-damaged chromatin (Fig. 5a, b).

To further confirm that PDDF are transcriptionally silent, we performed immunogold electron microscopy for detecting RNA polymerase II (pol II), the enzyme that directs the transcription of protein-coding genes [29]. We used the antibody $\mathrm{H} 5$ which recognizes the active RNA pol II, hyperphosphorylated on Ser2, which is involved in the elongation phase of transcription [29, 30]. In accordance with the 5'-FU transcription assay, immunogold particles were absent from PDDF, although they decorated flanking euchromatin and other euchromatin regions (Fig. 5d).

\section{Spatial organization of PDDF and their associations with nuclear compartments}

PDDF appeared in euchromatin domains, but they were apparently not randomly distributed within the neuronal nucleus. The quantitative analysis in SGNs immunolabeled for $\gamma \mathrm{H} 2 \mathrm{AX}$ revealed that approximately $70 \%$ of PDDF were perinucleolar, whereas $20 \%$ were distributed at the nuclear periphery and the remainder was located in other nuclear regions (Fig. 1f). Double immunolabeling for fibrillarin, a nucleolar marker [28], and 53BP1 confirmed the preferential spatial association of PDDF with the nucleolus (Fig. 6a). In this perinucleolar localization, PDDF frequently associated with Cajal bodies immunolabeled for fibrillarin (Fig. 6b) or coilin (Fig. 6c), a specific Cajal body marker [31-33]. Furthermore, a close association between PDDF and heterochromatin clumps, immunolabeled for the histone H4K20me3 or HP1Y (heterochromatin protein $1 \gamma$ ), was also observed at both perinucleolar and peripheral domains (Fig. 6d, e). Thus PDDF established spatial associations, but not co-localization, with a triad of nuclear structures: nucleolus, Cajal bodies and heterochromatin clumps. Occasional associations between PDDF and nuclear speckles immunostained with the antiTMG-cap antibody, which recognizes the 5 ' end of spliceosomal snRNAs [26], were detected (Fig. 6f). Immunogold electron microscopy with anti-fibrillarin and anti-coilin antibodies confirmed the association of PDDF with both Cajal bodies and nucleolus at the perinucleolar compartment (Fig. 7a, b). Similarly, the association of PDFF with both heterochromatin clumps and interchromatin granule clusters was validated with immunogold electron microscopy with the anti-53BP1 antibody (Fig. 7c). 

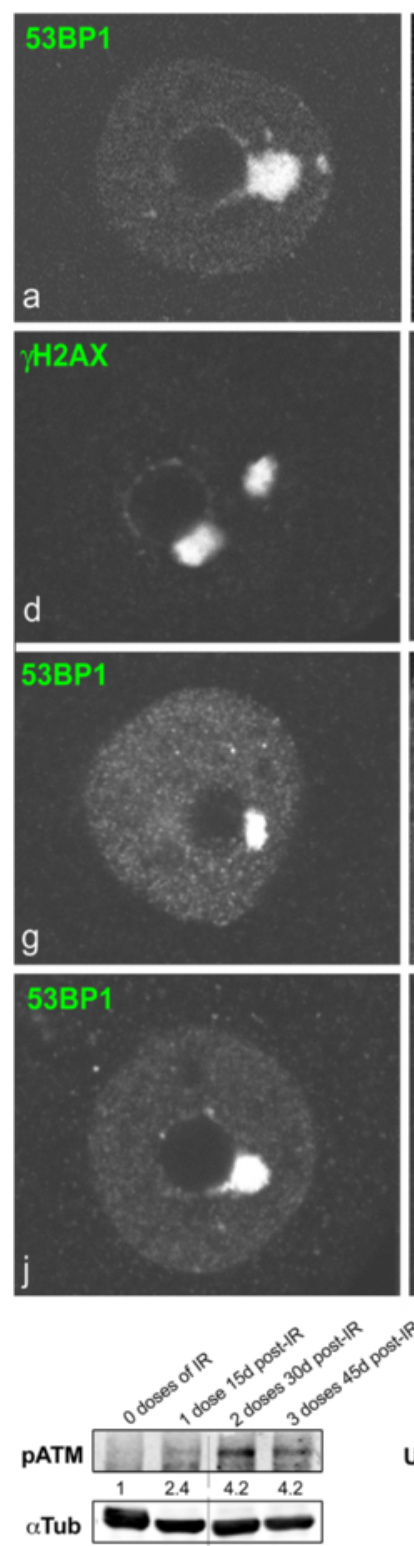

$\mathrm{m}$
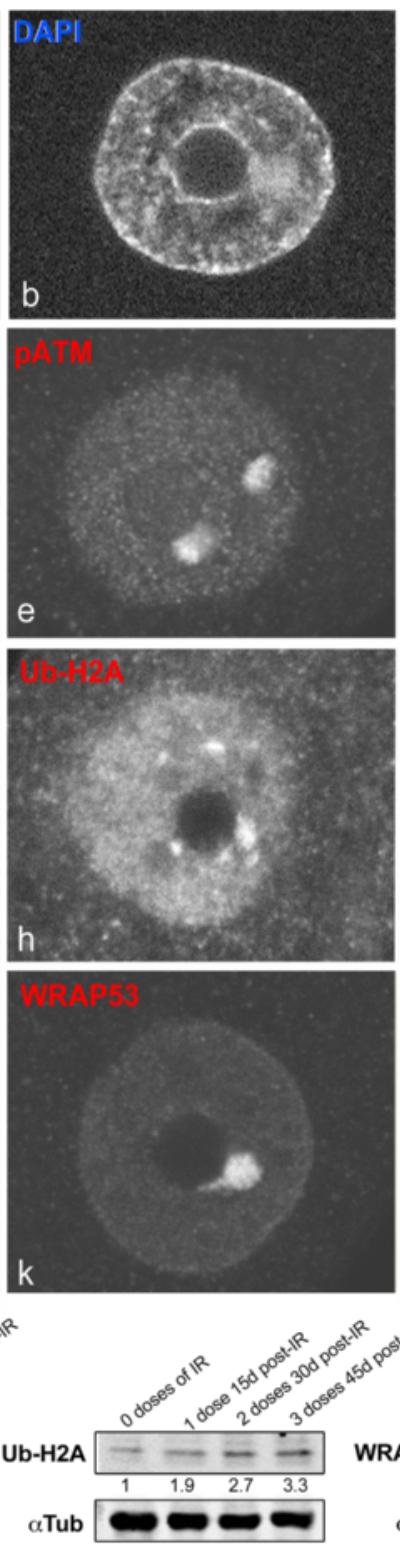

$\mathrm{n}$

0
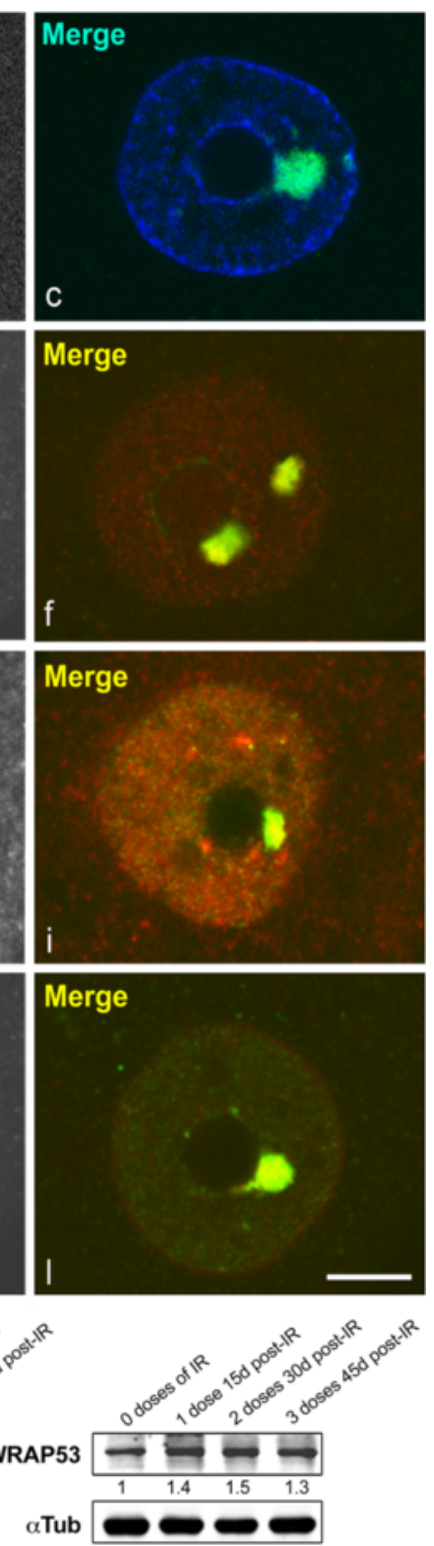

Fig. 2 a-c Immunostaining of SGNs nuclei for 53BP1 in combination with DAPI demonstrated the presence of DNA in a PDDF. 45d post-IR. d-I Double immunolabeling for $\mathrm{yH} 2 \mathrm{AX}$ in combination with pATM (d-f), and 53BP1 in combination with either Ub-H2A (g-i) or WRAP53 (j-l) demonstrated the colocalization of all these DNA damage signaling and repair factors in PDDF. 45d post-IR. Scale bar: $\mathbf{a}-\mathrm{I}=5 \mu \mathrm{m}$. $\mathbf{m}-\mathbf{o}$ Western blot analysis of the expression levels of pATM ( $\mathbf{m})$, Ub-H2A (n) and WRAP53 (o) in sensory ganglion of non-irradiated and irradiated rats exposed to one, two or thee doses of IR (4Gy each; $n=3$ animals per group). Note the induction of pATM after IR, and the dose-dependent substantial increase of both pATM and Ub-H2A protein levels. A moderate increase over the basal levels in control ganglion of WRAP53 was also observed upon IR. The expression of alpha-tubulin band was used as a protein loading control, and the fold increase estimated

\section{Discussion}

Our results in healthy SGNs exposed to sub-lethal doses of IR for inducing DSBs demonstrate that unrepaired DNA is retained for extended periods of time, up to 45 days in our study, in a few PDDF. The number and size of these foci is dependent on the total dose of IR, indicating a direct relationship between DNA damage accumulation and PDDF formation. PDDF are not simply static DNA damage "scars" of the genome, but in fact dynamic and specifically compartmentalized chromatin domains that recruit essential factors for signaling and repair DNA, such as $\gamma \mathrm{H} 2 \mathrm{AX}, \mathrm{pATM}, \mathrm{Ub}-\mathrm{H} 2 \mathrm{~A}$ and WRAP53. Furthermore, the progressive reduction of SGNs carrying PDDF over time of post-IR reported here supports that a slower DNA repair is still ongoing in some foci. This is consistent with the permanent enrichment of DNA 

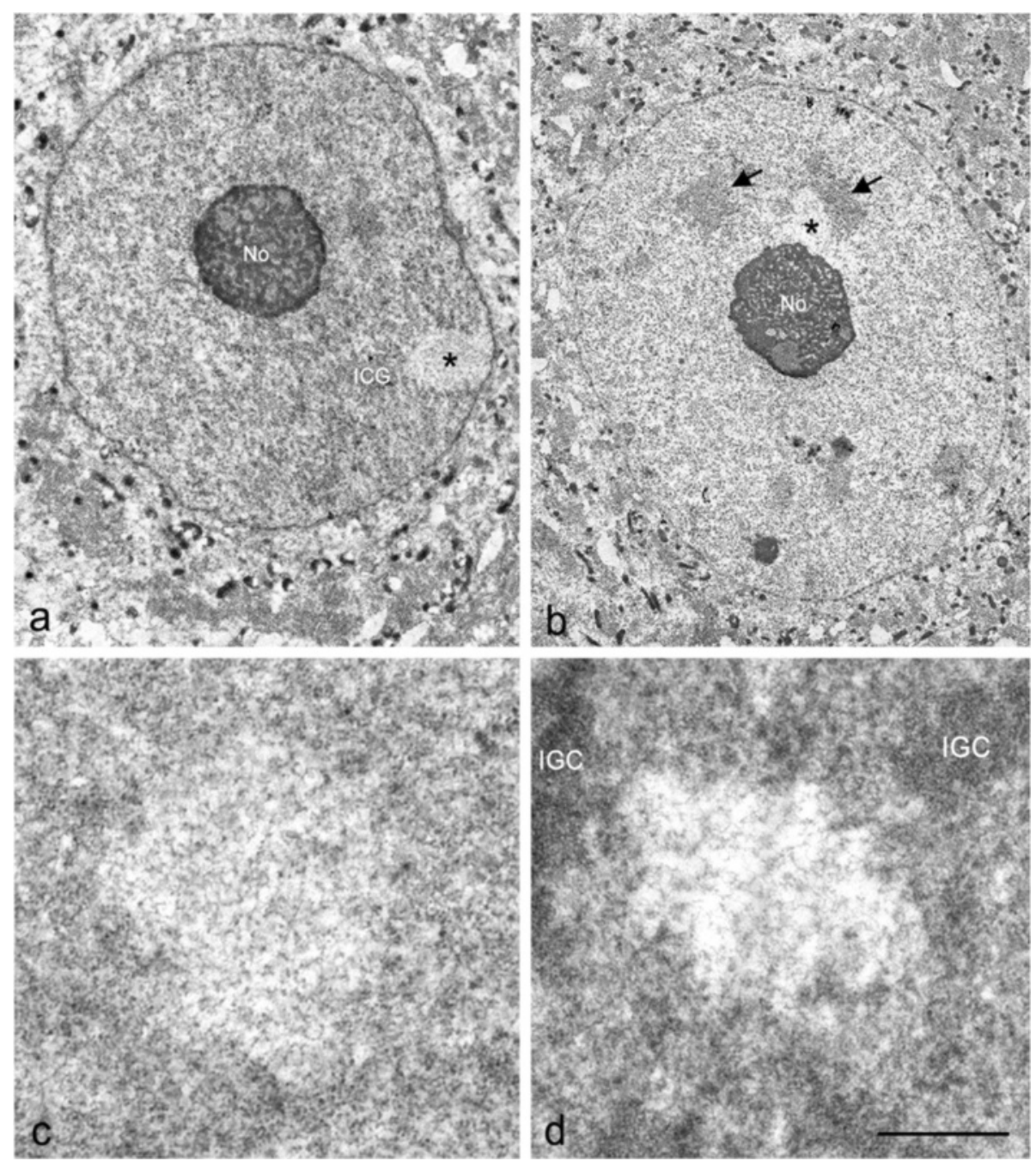

Fig. 3 Electron micrographs of SGN nuclei illustrating the structure and organization of PDDF. 45d post-IR. a, b PDDF (asterisks) appeared as cleared areas in the euchromatin landscape associated with the nuclear envelope or with the nucleolus (No). Interchromatin granule clusters (arrows). Scale bar: $5 \mu$ m. c, $\mathbf{d}$ Detailed fine structure of a PDDF composed of a loosen network of chromatin fibers surrounded by euchromatin. Scale bar: $1 \mu \mathrm{m}$. Cytochemical staining for ribonucleoproteins revealed the lack of weak staining of a PDDF, whereas the adjacent euchromatin and, particularly, the interchromatin granule clusters (IGC) appeared intensely contrasted. Scale bar: $1 \mu \mathrm{m}$

damage signaling and repair factors in PDDF, independently of the post-IR time and the total dose of IR administered. Our study provides the first analysis on the organization and dynamics of persistent foci of damaged DNA in neurons.

Regarding the possible pathophysiological implications of the accumulation of unrepaired DNA damage in neuronal PDDF, the loss of genomic integrity may contribute to both cognitive ageing and the pathogenesis of neurodegenerative diseases [5, 12,34]. An important challenge in this context is to understand how neurons can tolerate the accumulation of DNA damage and what is the threshold in DNA lesions that trigger neurodegeneration. Neurons are particularly vulnerable to DNA damage because their high metabolic rate which generates ROS. Moreover, it is believed that neurons have a decreased ratio of antioxidant to pro-oxidant enzymes that may potentially result in a state of elevated oxidative stress and DNA damage [35]. Importantly, recent studies demonstrate that the high transcriptional activity in a subset of genes that govern crucial neuronal functions, such as early-response genes, can trigger the formation of DSBs $[34,36]$. The generation of DSBs is mediated by the activity of topoisomerase II $\beta$, an enzyme which is robustly expressed in neurons and linked to transcription-related functions [37]. The transcription activity-induced DSBs in a physiological context raises the question of whether the accumulation of unrepaired or erroneously repaired DSBs could result in the formation of PDDF, and potentially contribute to the pathogenesis of neurological diseases [36]. In support 

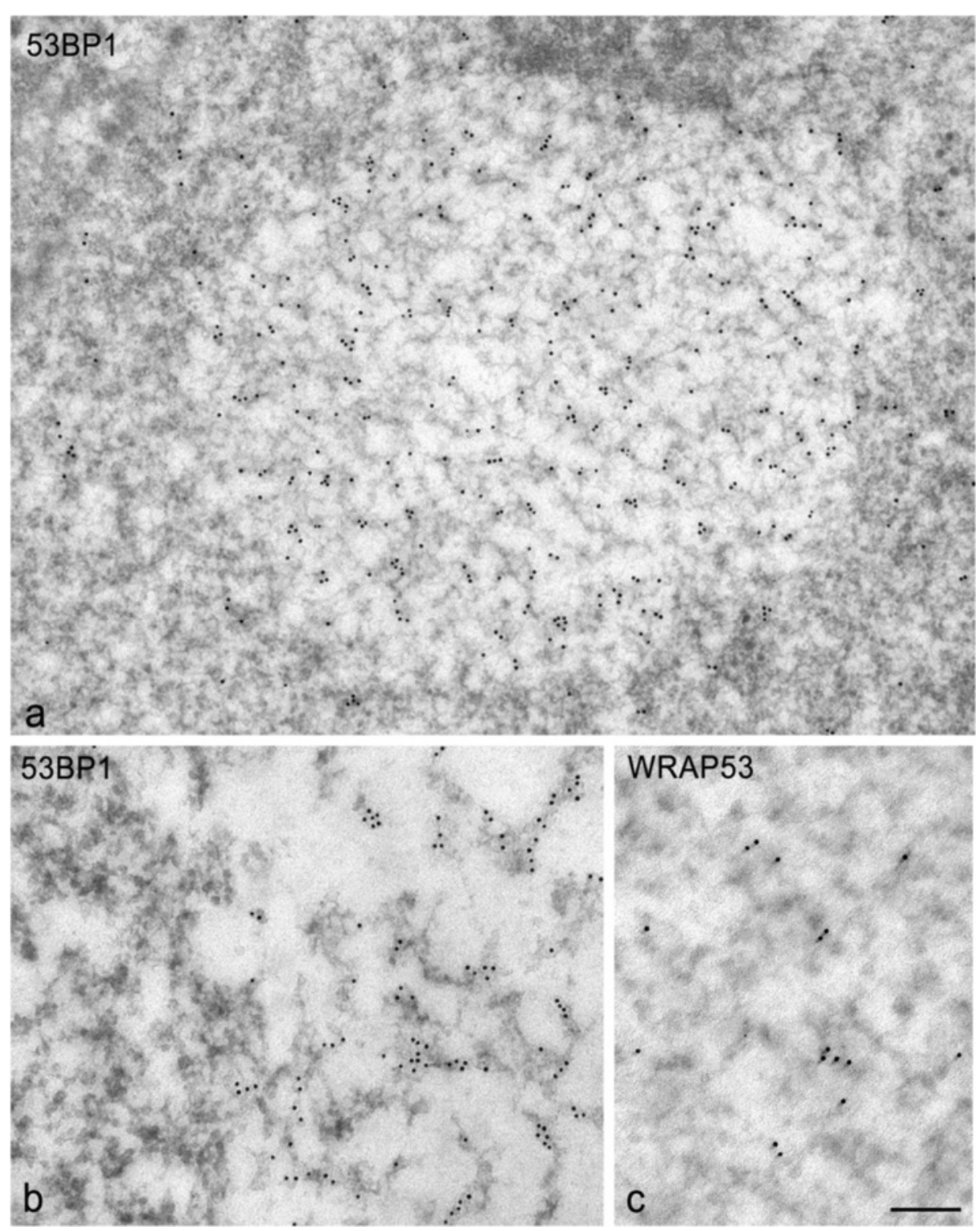

Fig. 4 Immunogold electron microscopy for the detection of 53BP1 (a, b) and WRAP53 (c) in PDDF. 45d post-IR. Immunogold particles of 53BP1 immunoreactivity strongly decorated the network of chromatin fibers throughout the focus. c Similarly, immunogold labeling for WRAP53 was also detected on the fibers. Scale bar: $a=175 \mathrm{~nm}, b=150 \mathrm{~nm}, c=125 \mathrm{~nm}$

of this notion, we have found PDDF in approximately $5 \%$ of non-irradiated SGNs. In this vein, the normal production of DSBs under physiological conditions is exacerbated by the neuronal accumulation of $\beta$-amyloid in a murine model of Alzheimer disease [34].

In the case of SGNs, increased vulnerability to DNA damage occurs due to the absence of blood brain barrier in peripheral ganglia that facilitates the access of genotoxic agents, including drugs used in cancer chemotherapy [38-40]. Indeed, DNA damage in SGN seems to be an important component in the long-term peripheral neurotoxicity of anticancer chemotherapy [15, 41].
An important aspect of our results is the neuronal asymmetry in the kinetics of DDR. Indeed, PDDF appear in approximately $30 \%$ of the global population of SGNs at 15 days post-IR while the majority of neurons lack PDDF, indicating effective DNA repair. Different lines of evidence suggest that the kinetics of DDR is related to the individual pattern of transcriptional activity. For example, active neurons break and repair their DNA more often than their less active, "resting", neighbours, resulting in broad differences in accumulated DNA lesions which will become progressively apparent in the long term [5]. 

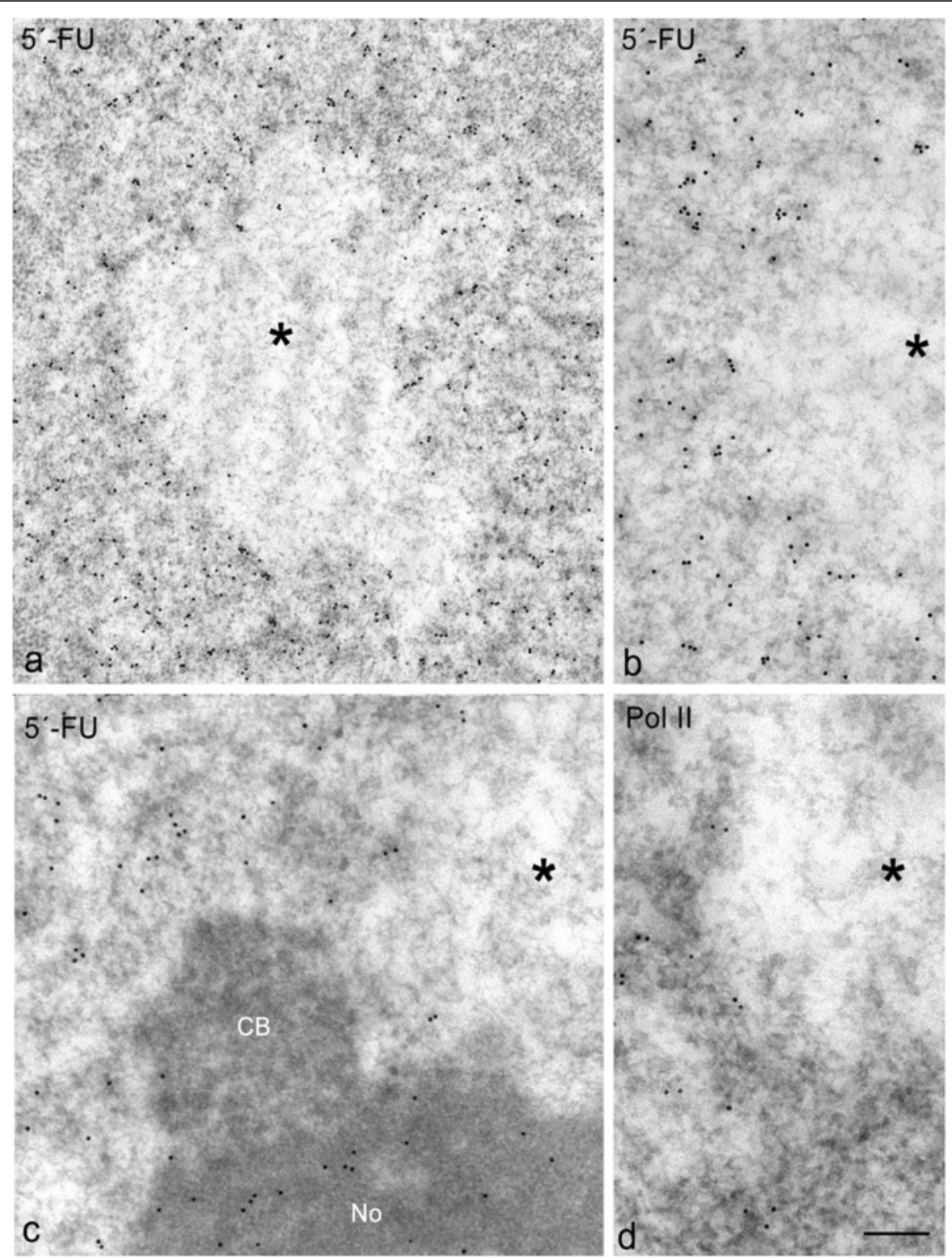

Fig. 5 Immunogold electron microscopy transcription assay based on the incorporation of 5'-FU into nascent RNA after 45 min of the intraperitoneal administration of 5'-FU. 45d post-IR. a This PDDF (asterisk) lack of immunogold labeling indicating the absence of transcription. However, the euchromatin, including de domains flanking the PDDF appeared intensely labeled with gold particles of 5'-FU incorporation. Scale bar: $300 \mathrm{~nm}$. b Detailed of 5'-FU incorporation in the euchromatin boundary of a PDDF (asterisk). Scale bar: $200 \mathrm{~nm}$. c Detail of a PDDF (asterisk) associated with both the nucleolus (No) and a Cajal Body (CB). Note the absence of nascent RNA in the PDDF and in the transcription-free CB, whereas the nucleolus and adjacent euchromatin appeared immunogold labeled. $\mathbf{d}$ Immunogold electron microscopy for the active RNA polymerase II shows the absence of labeling in a PDDF (asterisk), whereas the surrounding euchromatin appeared decorated with gold particles Scale bar: $150 \mathrm{~nm}$

Concerning the structural organization of PDDF reported here, it is well-known in non-neuronal cultured cell lines that DDR occurs in the chromatin landscape. Thus, the DDR requires local modifications in chromatin structure that first become more decondensed and accessible to DNA repair factors, followed by restoration of chromatin organization upon completion of DNA repair [1, 13, 42, 43]. Essential factors for these chromatin modifications are posttranslational modifications of histones, including phosphorylation of the $\mathrm{H} 2 \mathrm{AX}$ and ubiquitylation of $\mathrm{H} 2 \mathrm{~A}$ and $\mathrm{H} 2 \mathrm{~B}$, as well as chromatin chaperones and ATP-dependent remodeling factors [44]. Our electron microscopy findings in SGNs allowed us to characterize chromatin modifications in neuronal PDDF. Important hallmarks of PDDF are the super-relaxation of chromatin, which appears as cleared nuclear areas, 

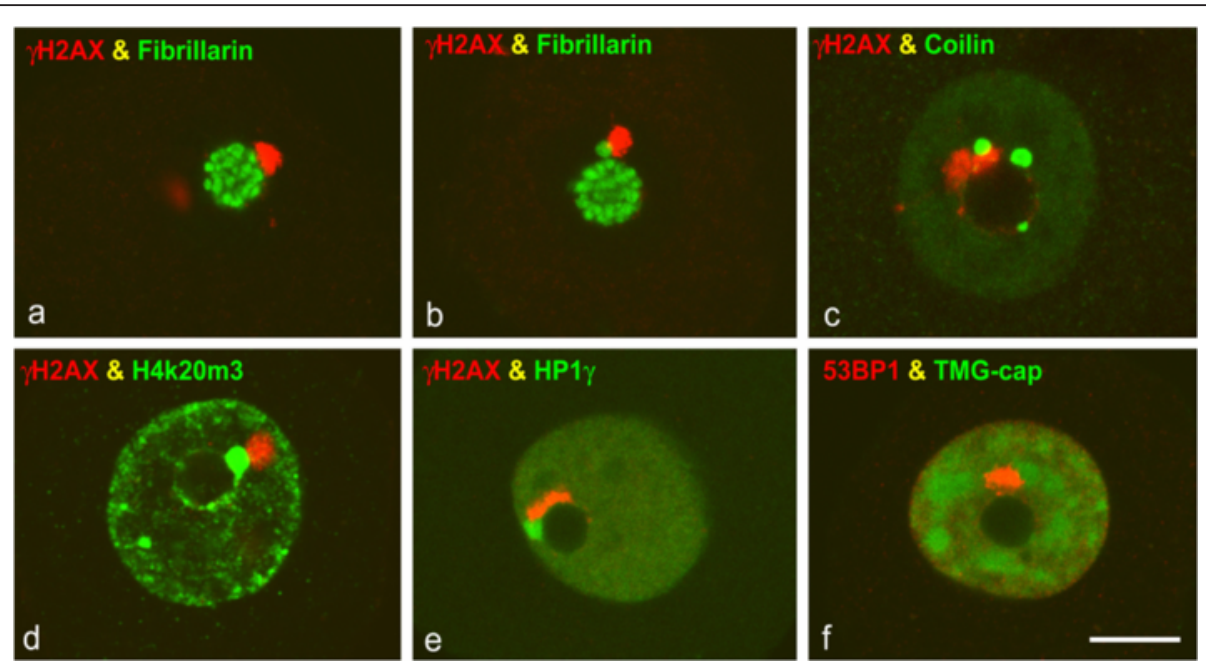

Fig. 6 a-e Confocal microscopy images of SGN nuclei co-stained for $\mathrm{YH} 2 \mathrm{AX}$ in combination with fibrillarin (a, b), coilin (c), histone H4K20me3 (d) and HP1Y (e). They illustrate the direct association of PDDF with a triad of structures: the nucleolus (a, c, e), Cajal bodies, immunolabeled for fibrillarin (b) or coilin (c), and perinucleolar heterochromatin clumps immunolabled for the tri-methylated histone H4K20me3 (d) or HP1Y (e). f Double immunolabeling for 53BP1 and TMG-cap illustrate the distribution of the nuclear speckles of splicing factors labelled with the anti-TMG-cap antibody and the close association of a PDDF with a speckle in the vicinity of the nucleolus. $45 \mathrm{~d}$ post-IR. Scale bar $=5 \mu \mathrm{m}$

the sharp boundary between damaged chromatin and the adjacent euchromatin, and the complete transcriptional silencing. The existence of cleared nuclear areas was initially reported in the classical study of Cavanagh et al. [38] in rat SGNs treated with adriamycin, a genotoxic drug used in chemotherapy, although the authors did not relate this finding with DNA damage. Interestingly, the large-scale chromatin decompaction in PDDF occurs in an euchromatic environment, while heterochromatin clumps lack immunolabeling for DNA damage and repair factors. This indicates the higher vulnerability to DNA damage of the euchromatin, which is transcriptionally active or poised for activation [45]. The fine structure of PDDF is characterized by a loose network of fibers ranging from $30 \mathrm{~nm}$ chromatin fibers [46] to $11 \mathrm{~nm}$. This finding supports the notion that unfolded $30 \mathrm{~nm}$ fiber intermediates provide a structural scaffold which is accessible for signaling and repair factors, as the selective and strong 53BP1 immunogold labeling of the fibers reflects. Therefore, the relaxed state of chromatin in PDDF fits the requirement for DNA repair process, which takes place on exposed DNA [47]. Furthermore, two of the factors enriched in neuronal PDDF, WRAP53 and Ub-H2A, have been implicated in DNA repair in cellular models of DNA damage. Mechanistically, WRAP53 targets the ubiquitin E3 ligase RNF8 to DSBs where ubiquitylated histones $\mathrm{H} 2 \mathrm{~A}$ and $\mathrm{H} 2 \mathrm{AX}$ promote the assembly of repair factor such as 53BP1 [22, 24].

The sharp ultrastructural boundary between the damaged chromatin of PDDF and adjacent euchromatin supports that unrepaired genes congregate and isolate in these damage/repair foci to reduce genome instability and preserve global transcription in undamaged euchromatin. We hypothesized that the sequestration of DNA lesions in one or two individual PDDF allows the neuron to tolerate the accumulation of unrepaired DNA without triggering apoptotic pathways. The molecular barriers between damaged and undamaged chromatin in PDDF are unknown. Interestingly, a recent molecular study, using a new cellbased DSB inducible system to characterize the chromatin landscape around DSB, demonstrates that the recruitment of cohesin prevents $\gamma \mathrm{H} 2 \mathrm{AX}$ spreading [48]. The authors propose that, in addition to the function in chromatin architecture, cohesin helps to isolate active genes from damaged ones carrying DSBs. The compartmentalization of neuronal DNA damage might involve DSB-containing chromosome domains moving over relatively large distances to be clustered in PDDF. This interpretation is consistent with previous observations in cell lines revealing increased mobility of the break sites upon IR treatment $[49,50]$. Accordingly, in yeast and mammalian cell lines exposed to IR, the formation of DSBs in the nucleolus and heterochromatin results in the movement and relocalization of breaks to the periphery of these nuclear structures [51, 52].

Our results provide the first demonstration of a complete transcriptional silencing at DNA damage foci in neurons. Three lines of evidence support gene silencing within PDDF: i) the total absence of 5'-FU incorporation, a precursor for RNA synthesis, demonstrated with the high resolution of the immunogold electron microscopy, ii) the absence of immunogold labeling for the RNA polymerase II phosphorylated on Ser 2, a well established marker of the elongation phase of transcription $[29,53]$, 

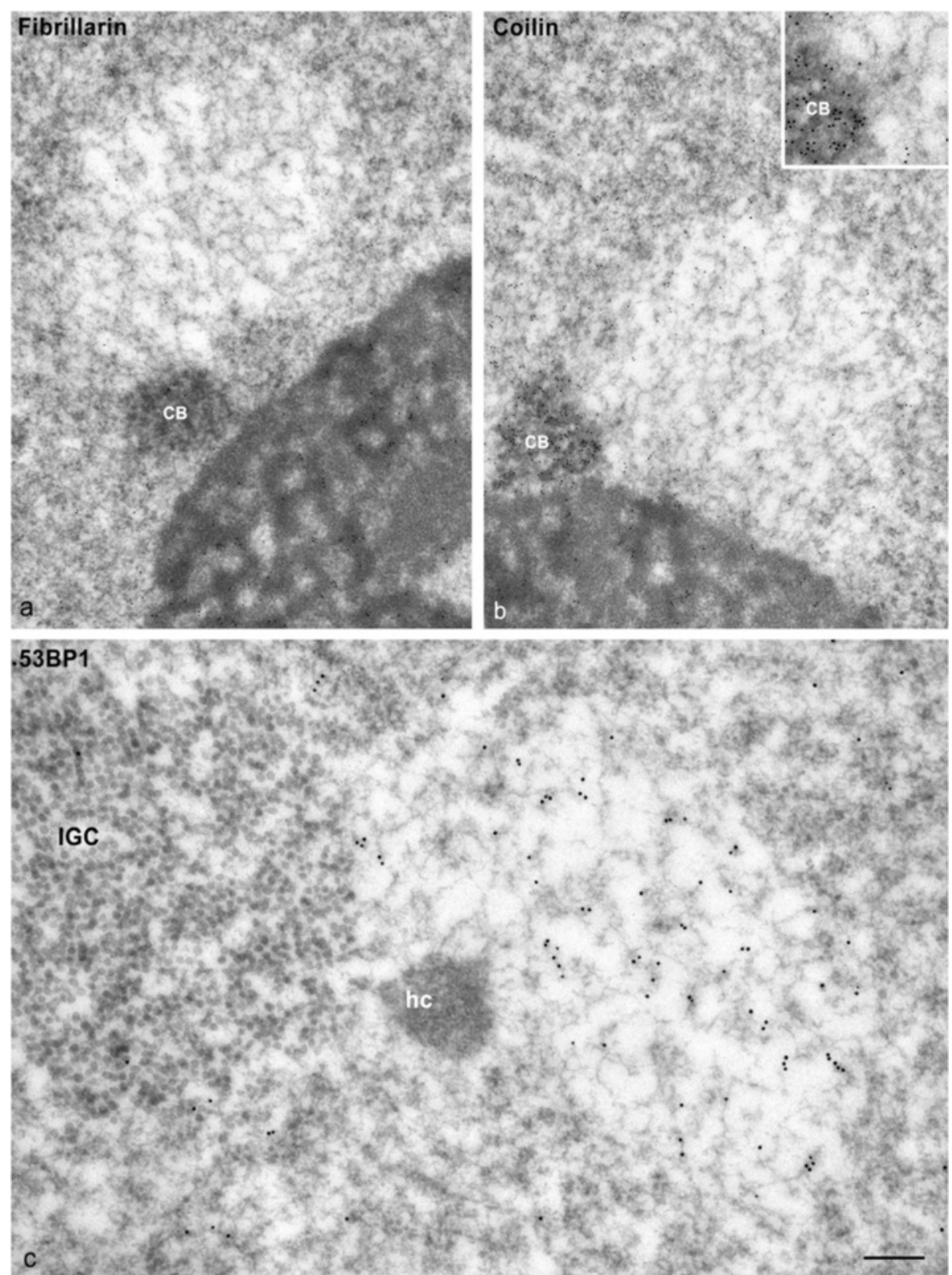

Fig. 7 a, b Immunogold electron microscopy illustrating the direct association of PDDF with the nucleolus and a Cajal body labeled with the anti-fibrillarin antibody (a), and the nucleolus and a coilin-positive Cajal body (b). c A 53BP1-positive PDDF appears associated with a cluster of interchromatin granules (IGC) and a heterochromatin mass (hc). Scale bar: $a=500 \mathrm{~nm}, b=400 \mathrm{~nm}$ and $c=100 \mathrm{~nm}$

and iii) the lack of concentration of RNAs, as indicated the preferential cytochemical staining for ribonucleoproteins [25]. Moreover, transcriptional repression corresponds exactly to the local distribution of $\gamma \mathrm{H} 2 \mathrm{AX}$, which spreads on the entire PDDF but does not propagate on active genes in adjacent euchromatin. Therefore, the expression of $\gamma \mathrm{H} 2 \mathrm{AX}$ can be used as a reliable marker of gene silencing in DNA damaged neurons. Transcriptional silencing at PDDF can be essential to reduce genome instability by preventing the synthesis of aberrant mRNA and protein products encoded by damaged genes. In accordance with the PDDF enrichment in p-ATM and Ub-H2A, recent molecular studies have reported an ATM-dependent transcriptional repression at DSBs mediated by $\mathrm{H} 2 \mathrm{~A}$ ubiquitylation, whereas deubiquitylation of $\mathrm{H} 2 \mathrm{~A}$ restores transcription [23].

An intriguing aspect of PDDF is their preferential spatial association with the nucleolar and less frequently, nuclear periphery. Interestingly, both nuclear domains are enriched in constitutive heterochromatin, characterized by the 
abundance of repeated DNA sequences and the binding of HP1 proteins, and correlates with transcriptional silencing $[54,55]$. Positioning of PDDF at these repressive nuclear environments may facilitate transcriptional silencing of damaged genes and contribute to maintain genomic stability within PDDF. Alternatively, but not mutually exclusive, nucleolus- and heterochromatinassociated PDDF may represent repair centers for damaged ribosomal genes and repeated DNA sequences of heterochromatin, respectively. In this vein, in nonneuronal culture cell lines exposed to IR, the relocation of DSBs have been reported from the initial induction site in the nucleolus or heterochromatin to the periphery of both structures [51, 52, 56, 57]. Further ChIP-seq analysis of the $\gamma \mathrm{H} 2 \mathrm{AX}$-binding DNA will be necessary to determine what genes are enriched in neuronal PDDF, and particularly if they contain damaged ribosomal genes and repeated sequences of heterochromatin.

\section{Conclusion}

In conclusion, our results strongly indicate that unrepaired DNA in neurons is sequestrated in one to three discrete PDDF of transcriptionally silent chromatin. This transcriptional silencing can be essential to preserve genome stability and prevent the synthesis of aberrant mRNA and protein products encoded by damaged genes. Moreover, the expression of $\gamma \mathrm{H} 2 \mathrm{AX}$ can be used as a reliable marker of gene silencing in DNA damaged neurons.

\section{Ethical approval}

All procedures were approved by the Bioethical Committee of the University of Cantabria, and were carried out according to the directives of the Council of the European Communities and current Spanish legislation.

\section{Competing interests}

The authors declare that they have no competing interests.

\section{Authors' contributions}

ML and MTB designed the study and wrote the manuscript. JM-G and IC performed the immunocytochemistry experiments and the quantitative analysis. $\mathrm{ML}$ carried out the electron microscopystudy. OT performed the Western blotting experiments. All the authors analyzed the results, and read and approved the final manuscript.

\section{Acknowledgements}

The authors wish to thank Raquel García Ceballos for technical assistance. This work was supported by the following grants: "Dirección General de Investigación" (BFU2011-23983; BFU2014-54754-P) and "Centro de Investigación Biomédica en Red sobre Enfermedades Neurodegenerativas" (CIBERNED; CB06/05/0037) Spain.

Received: 16 March 2016 Accepted: 11 April 2016

Published online: 22 April 2016

\section{References}

1. Ziv Y, Bielopolski D, Galanty Y, Lukas C, Taya Y, Schultz DC, Lukas J, BekkerJensen S, Bartek J, Shiloh Y. Chromatin relaxation in response to DNA double-strand breaks is modulated by a novel ATM- and KAP-1 dependent pathway. Nat Cell Biol. 2006;8:870-6.
2. Misteli T, Soutoglou E. The emerging role of nuclear architecture in DNA repair and genome maintenance. Nat Rev Mol Cell Biol. 2009;10:243-54.

3. Casafont I, Palanca A, Lafarga V, Berciano MT, Lafarga M. Effect of ionizing radiation in sensory ganglion neurons: organization and dynamics of nuclear compartments of DNA damage/repair and their relationship with transcription and cell cycle. Acta Neuropathol. 2011;122:481-93.

4. Ferrer I, Serrano T, Alcantara S, Tortosa A, Graus F. X-ray-induced cell death in the developing hippocampal complex involves neurons and requires protein synthesis. J Neuropathol Exp Neurol. 1993;52:370-8.

5. Chow HM, Herrup K. Genomic integrity and the ageing brain. Nat Rev Neurosci. 2015;16:672-84.

6. Pan L, Penney J, Tsai LH. Chromatin regulation of DNA damage repair and genome integrity in the central nervous system. J Mol Biol. 2014;426:3376-88.

7. Lieber MR. The mechanism of double-strand DNA break repair by the nonhomologous DNA end-joining pathway. Ann Rev Biochem. 2010;79:181-211.

8. Madabhushi R, Pan L, Tsai LH. DNA damage and its links to neurodegeneration. Neuron. 2014;83:266-82.

9. Sedelnikova OA, Horikawa I, Zimonjic DB, Popescu NC, Bonner WM, Barrett JC. Senescing human cells and ageing mice accumulate DNA lesions with unrepairable double-strand breaks. Nat Cell Biol. 2004;6:168-70.

10. Rass $U$, Ahel I, West SC. Defective DNA repair and neurodegenerative disease. Cell. 2007;130:991-1004.

11. Baltanas F, Casafont I, Lafarga V, Weruaga E, Alonso JR, Berciano MT, Lafarga M. Purkinje cell degeneration in pcd mice reveals large scale chromatin reorganization and gene silencing linked to defective DNA repair. J Biol Chem. 2011;286:28287-302.

12. McKinnon PJ. Maintaining genome stability in the nervous system. Nat Neurosci. 2013;16:1523-9.

13. Soria G, Polo SE, Almouzni G. Prime, repair, restore: the active role of chromatin in the DNA damage response. Mol Cell. 2012;46:722-34.

14. Cavaletti G, Marmiroli P. Chemotherapy-induced peripheral neurotoxicity. Nat Rev Neurol. 2010;6:657-66.

15. Palanca A, Casafont I, Berciano MT, Lafarga M. Proteasome inhibition induces DNA damage and reorganizes nuclear architecture and protein synthesis machinery in sensory ganglion neurons. Cell Mol Life Sci. 2014;71:1961-75.

16. Pena E, Berciano MT, Fernandez R, Ojeda JL, Lafarga M. Neuronal body size correlates with the number of nucleoli and Cajal bodies, and with the organization of the splicing machinery in rat trigeminal ganglion neurons. J Comp Neurol. 2001;430:250-63.

17. Fernandez-Capetillo O, Lee A, Nussenzweig M, Nussenzweig A. H2AX: the histone guardian of genome. DNA Repair. 2004;3:959-67.

18. Ismail $\mid H$, Hendzel MJ. The gamma-H2A.X: is it just a surrogate marker of double-strand breaks or much more? Environ Mol Mutagen. 2008;49:73-82.

19. Bothmer A, Robbiani DF, Feldhahn N, Gazumyan A, Nussenzweig A, Nussenzweig MC. 53BP1 regulates DNA resection and the choice between classical and alternative end joining during class switch recombination. J Exp Med. 2010;207:855-65.

20. Panier S, Boulton SJ. Double-strand break repair: 53BP1 comes into focus. Nat Rev Mol Cell Biol. 2014;15:7-18.

21. Stiff T, O'Driscoll M, Rief N, Iwabuchi K, Löbrich M, Jeggo PA. ATM and DNAPK function redundantly to phosphorylate $\mathrm{H} 2 \mathrm{AX}$ after exposure to ionizing radiation. Cancer Res. 2004;64:2390-6.

22. Mailand N, Bekker-Jensen S, Faustrup H, Melander F, Bartek J, Lukas C, Lukas J. RNF8 ubiquitylates histones at DNA double-strand breaks and promotes assembly of repair proteins. Cell. 2007;131:887-900.

23. Shanbhag NM, Rafalska-Metcalf IU, Balane-Bolivar C, Janicki SM, Greenberg RA. ATM-dependent chromatin changes silence transcription in cis to DNA double-strand breaks. Cell. 2010;141:970-81.

24. Henriksson S, Rassoolzadeh H, Hedström E, Coucoravas C, Julner A, Goldstein M, Imreh G, Zhivotovsky B, Kastan MB, Helleday T, Farnebo M. The scaffold protein WRAP53 $\beta$ orchestrates the ubiquitin response critical for DNA double-strand break repair. Genes Dev. 2014;28:2726-38.

25. Bernhard W. A new staining procedure for electron microscopical cytology. J Ultrastruct Res. 1969;27:250-65.

26. Lamond Al, Spector DL. Nuclear speckles: a model for nuclear organelles. Nat Rev Mol Cell Biol. 2003;4:605-12.

27. Dorigo B, Schalch T, Kulangara A, Duda S, Schroeder RR, Richmond TJ, Nucleosome arrays reveal the two-start organization of the chromatin fiber. Science. 2004;306:1571-3.

28. Raska I, Shaw PJ, Cmarko D. New insights into nucleolar architecture and activity. Int Rev Cytol. 2006;255:177-235. 
29. Jonkers I, Lis JT. Getting up to speed with transcription elongation by RNA polymerase II. Nat Rev Mol Cell Biol. 2015;16:167-77.

30. Guillot PV, Xie SQ, Hollinshead M, Pombo A. Fixation-induced redistribution of hyperphosphorylated RNA polymerase II in the nucleus of human cells. Exp Cell Res. 2004;295:460-8.

31. Raska I, Ochs RL, Andrade LE, Chan EK, Burlingame R, Peebles C, Gruol D, Tan EM. Association between the nucleolus and the coiled body. J Struct Biol. 1990;104:120-7.

32. Carvalho T, Almeida F, Calapez A, Lafarga M, Berciano MT, CarmoFonseca M. The spinal muscular atrophy disease gene product, SMN: A link between snRNP biogenesis and the Cajal (coiled) body. J Cell Biol. 1999;147:715-28.

33. Cioce M, Lamond Al. Cajal bodies: a long history of discovery. Annu Rev Cell Dev Biol. 2005;21:105-31.

34. Suberbielle E, Sanchez PE, Kravitz AV, Wang X, Ho K, Eilertson K, Devidze N, Kreitzer AC, Mucke L. Physiologic brain activity causes DNA double-strand breaks in neurons, with exacerbation by amyloid- $\beta$. Nat Neurosci. 2013;16: 613-21.

35. Canugovi C, Misiak M, Ferrarelli LK, Croteau DL, Bohr VA. The role of DNA repair in brain related disease pathology. DNA Repair. 2013;12:578-87.

36. Madabhushi R, Gao F, Pfenning AR, Pan L, Yamakawa S, Seo J, Rueda R, Phan TX, Yamakawa H, Pao PC, Stott RT, Gjoneska E, Nott A, Cho S, Kellis M, Tsai LH. Activity-induced DNA breaks govern the expression of neuronal early-response genes. Cell. 2015;1617:1592-605.

37. Austin CA, Marsh KL. Eukaryotic DNA topoisomerase II beta. Bioessays. 1998;20:215-26

38. Cavanagh JB, Tomiwa K, Munro PM. Nuclear and nucleolar damage in adriamycin-induced toxicity to rat sensory ganglion cells. Neuropathol Appl Neurobiol. 1987;13:23-38.

39. Pena E, Berciano MT, Fernandez R, Crespo P, Lafarga M. Stress-induced activation of c-Jun N-terminal kinase in sensory ganglion neurons: accumulation in nuclear domains enriched in splicing factors and distribution in perichromatin fibrils. Exp Cell Res. 2000;256:179-91.

40. Casafont I, Navascués J, Pena E, Lafarga M, Berciano MT. Nuclear organization and dynamics of transcription sites in rat sensory ganglia neurons detected by incorporation of 5'-fluororidine into nascent RNA. Neuroscience. 2006;140:453-62.

41. Alberti $\mathrm{P}$, Cavaletti G. Management of side effects in the personalized medicine era: chemotherapy-induced peripheral neuropathy. Methods Mol Biol. 2014;1175:301-22

42. Kruhlak MJ, Celeste A, Dellaire G, Fernandez-Capetillo O, Müller WG, McNally $J G$, et al. Changes in chromatin structure and mobility in living cells at sites of DNA double-strand breaks. J Cell Biol. 2006;172:823-34.

43. Dellaire G, Kepkay R, Bazett-Jones DP. High resolution imaging of changes in the structure and spatial organization of chromatin, $\mathrm{y}-\mathrm{H} 2 \mathrm{AX}$ and the MRN complex within etoposide-induced DNA repair foci. Cell Cycle. 2009:8:1-20.

44. Luijsterburg MS, van Attikum H. Chromatin and the DNA damage response: the cancer connection. Mol Oncol. 2011:5:349-67.

45. Maison C, Almouzni G. HP1 and the dynamics of heterochromatin maintenance Nat Rev Mol Cell Biol. 2004;5:296-304.

46. Tremethick DJ. Higher-order structures of chromatin: the elusive $30 \mathrm{~nm}$ fiber Cell. 2007;128:651-4.

47. Moyal L, Lerenthal Y, Gana-Weisz M, Mass G, So S, Wang SY, Eppink B, Chung YM, Shalev G, Shema E, Shkedy D, Smorodinsky NI, van Vliet N, Kuster B, Mann M, Ciechanover A, Dahm-Daphi J, Kanaar R, Hu MC, Chen DJ, Oren M, Shiloh Y. Requirement of ATM-dependent monoubiquitylation of histone $\mathrm{H} 2 \mathrm{~B}$ for timely repair of DNA double-strand breaks. Mol Cell. 2011;41:529-42.

48. Caron P, Aymard F, lacovoni JS, Briois S, Canitrot Y, Bugler B, Massip L Losada A, Legube G. Cohesin protects genes against $\gamma \mathrm{H} 2 \mathrm{AX}$ induced by DNA double-strand breaks. PLoS Genet. 2012;8:e1002460.

49. Aten JA, Stap J, Krawczyk PM, van Oven CH, Hoebe RA, Essers J, Kanaar R. Dynamics of DNA double-strand breaks revealed by clustering of damaged chromosome domains. Science. 2004;303:92-5.

50. Zhang Y, Heermann DW. DNA double-strand breaks: linking gene expression to chromosome morphology and mobility. Chromosoma. 2014;123:103-15.

51. Torres-Rosell J, Sunjevaric I, De Piccoli G, Sacher M, Eckert-Boulet N, Reid R, Jentsch S, Rothstein R, Aragón L, Lisby M. The Smc5-Smc6 complex and SUMO modification of Rad52 regulates recombinational repair at the ribosomal gene locus. Nat Cell Biol. 2007:9:923-31.
52. Chiolo I, Minoda A, Colmenares SU, Polyzos A, Costes SV, Karpen GH. Doublestrand breaks in heterochromatin move outside of a dynamic HP1a domain to complete recombinational repair. Cell. 2011;144732-44.

53. Casafont I, Palanca A, Lafarga V, Mata-Garrido J, Berciano MT, Lafarga M. Behavior of the RNA Polymerase II and the Ubiquitin Proteasome system during the neuronal DNA damage response to ionizing radiation. Mol Neurobiol. 2015. doi:10.1007/s12035-015-9565-8.

54. Padeken J, Heun P. Nucleolus and nuclear periphery: velcro for heterochromatin. Curr Opin Cell Biol. 2014;28:54-60.

55. Smirnov E, Cmarko D, Mazel T, Hornáček M, Raška I. Nucleolar DNA: the host and the guests. Histochem Cell Biol. 2016;145:359-72.

56. Jakob B, Splinter J, Conrad S, Voss KO, Zink D, Durante M, Löbrich M, Taucher-Scholz G. DNA double-strand breaks in heterochromatin elicit fast repair protein recruitment, histone $\mathrm{H} 2 \mathrm{AX}$ phosphorylation and relocation to euchromatin. Nucleic Acids Res. 2011:39:6489-99.

57. Harding SM, Boiarsky JA, Greenberg RA. ATM dependent silencing links nucleolar chromatin reorganization to DNA damage recognition. Cell Rep. 2015;13:251-9.

\section{Submit your next manuscript to BioMed Central and we will help you at every step:}

- We accept pre-submission inquiries

- Our selector tool helps you to find the most relevant journal

- We provide round the clock customer support

- Convenient online submission

- Thorough peer review

- Inclusion in PubMed and all major indexing services

- Maximum visibility for your research

Submit your manuscript at www.biomedcentral.com/submit 